\title{
Advantages of dynamic "closed loop" stable isotope flux phenotyping over static "open loop" clamps in detecting silent genetic and dietary phenotypes
}

\author{
Bhavapriya Vaitheesvaran · Fu-Yu Chueh • \\ Jun Xu $\cdot$ Chuck Trujillo $\cdot$ M. F. Saad $\cdot$ W. N. P. Lee $\cdot$ \\ Owen P. McGuinness • Irwin J. Kurland
}

Received: 31 August 2009/ Accepted: 29 October 2009/Published online: 12 November 2009

(C) The Author(s) 2009. This article is published with open access at Springerlink.com

\begin{abstract}
In vivo insulin sensitivity can be assessed using "open loop" clamp or "closed loop" methods. Open loop clamp methods are static, and fix plasma glucose independently from plasma insulin. Closed loop methods are dynamic, and assess glucose disposal in response to a stable isotope labeled glucose tolerance test. Using PPAR $\alpha^{-l-}$ mice, open and closed loop assessments of insulin sensitivity/glucose disposal were compared. Indirect calorimetry done for the assessment of diurnal substrate utilization/metabolic flexibility showed that chow fed $\operatorname{PPAR} \alpha^{-1-}$ mice had increased glucose utilization during the light (starved) cycle. Euglycemic clamps showed no differences in insulin stimulated glucose disposal, whether for chow or high fat diets, but did show differences in basal glucose clearance for chow fed PPAR $\alpha^{-1-}$ versus SV129Jwt mice. In contrast, the dynamic stable isotope labeled glucose tolerance tests reveal enhanced glucose disposal for PPAR $\alpha^{-1-}$ versus SV129J-wt, for chow and high fat diets. Area under the curve for plasma labeled and
\end{abstract}

B. Vaitheesvaran · J. Xu · C. Trujillo · I. J. Kurland ( $\bowtie)$ Department of Medicine, Albert Einstein College of Medicine, 1301 Morris Park Ave, Bronx, NY 10461, USA

e-mail: ikurland@aecom.yu.edu

F.-Y. Chueh · O. P. McGuinness

Department of Molecular Physiology and Biophysics,

Vanderbilt University, Nashville, TN, USA

W. N. P. Lee

Department of Pediatrics, LA Biomed Centre, Torrance, CA, USA

M. F. Saad

Department of Preventative Medicine, State University of New York, Stony Brook, NY, USA unlabeled glucose for $\operatorname{PPAR} \alpha^{-1-}$ was $\approx 1.7$-fold lower, $P<0.01$ during the stable isotope labeled glucose tolerance test for both diets. Area under the curve for plasma insulin was 5-fold less for the chow fed SV129J-wt $(P<0.01)$ but showed no difference on a high fat diet $\left(0.30 \pm 0.1\right.$ for SV129J-wt vs. $0.13 \pm 0.10$ for PPAR $\alpha^{-l-}$, $P=0.28$ ). This study demonstrates that dynamic stable isotope labeled glucose tolerance test can assess "silent" metabolic phenotypes, not detectable by the static, "open loop", euglycemic or hyperglycemic clamps. Both open loop and closed loop methods may describe different aspects of metabolic inflexibility and insulin sensitivity.

Keywords Orphan nuclear receptor action .

Stable isotope flux phenotyping · Metabolic flexibility

\section{Introduction}

Insulin sensitivity is an index, which measures the ability of endogenous insulin to lower glucose in extracellular fluids by inhibiting hepatic glucose release and stimulating the peripheral glucose consumption. Metabolic flexibility is the ability to dynamically switch between fatty acid and carbohydrates as fuel sources, between the fasted and fed states, respectively. It is defined by the capacity of the body or cells to match fuel oxidation to fuel availability and the endocrine environment (Galgani and Ravussin 2008). Disturbances in the reciprocal metabolic relationship between glucose and fatty acid utilization has been postulated to induce insulin resistance (reviewed in Kiens 2006). Frameworks for in vivo insulin resistance and metabolic inflexibility have been formulated to describe disturbances underlying the metabolic syndrome and/or Type II diabetes (Kelley 2005; Kelley and Mandarino 2000). 
In vivo insulin sensitivity is typically determined by the static flux assessment of an euglycemic clamp, which at a fixed basal glucose level, measures peripheral glucose disposal in response to an insulin increase (Ayala et al. 2006). Metabolic flexibility is most easily assessed continuously during the diurnal cycle in mice using indirect calorimetry (see Xu et al. 2006b for a detailed example). The frameworks of metabolic flexibility and insulin sensitivity seem to be inter-dependent, or in the very least, associated. It is not as yet clear, which may be affected first in the progression towards impaired glucose tolerance and Type II DM. Skeletal muscle prefers fatty acids to carbohydrate as a fuel source (Randle 1986; Randle 1995) and clearly, a mixed diet containing high fat induces insulin resistance, and metabolic inflexibility. Signaling cascades are also affected by the intracellular accumulation of lipids (Petersen and Shulman 2006; Shulman 2000) However, genetic defects possibly resulting in metabolic inflexibility may not be insulin resistant. The PPAR $\alpha$ null mouse model, having inherent defect in fatty acid oxidation (Desvergne et al. 2006) is such an example. Euglycemic clamp assessment in the high fat fed state shows no difference in glucose disposal for the PPAR $\alpha$ null mouse (Haluzik et al. 2004), despite glucose tolerance test studies showing protection against high fat diet induced hyperglycemia and hyperinsulinemia (Guerre-Millo et al. 2001). Even so, these conventional unlabeled glucose tolerance test studies showed no significant differences for PPAR $\alpha$ null mice versus SV129Jwt in the chow fed state. Thus the PPAR $\alpha$ null mouse model was considered to have a "silent" metabolic phenotype which could only be brought out by a high fat diet (Guerre-Millo et al. 2001).

Stable isotope flux phenotyping was able to discern the underlying flux compensations in the PPAR $\alpha$ null mouse in the chow fed state that maintained fuel homeostasis (Xu et al. 2002, 2004). Utilizing stable isotope flux phenotyping methodology, this study assesses in vivo insulin sensitivity in the setting of a dietary cause of metabolic inflexibility (high fat diet), using the PPAR $\alpha$ null-mouse as a model system. Our study also addresses whether static (euglycemic and hyperglycemic clamps) versus dynamic (stable isotope labeled glucose tolerance test) methodology may describe different aspects of insulin sensitivity, and how pertinent these differences are to the assessment of metabolic flexibility. It was found that dynamic stable isotope labeled glucose tolerance tests can assess "silent" metabolic phenotypes that the static euglycemic clamp cannot. Both the dynamic stable isotope labeled glucose tolerance test, and static measurements of basal glucose clearance, can aid indirect calorimetry for assessing metabolic flexibility/fuel utilization in mouse models of dysregulated metabolism.

\section{Materials and methods}

\subsection{Animals}

Mice were obtained from The Jackson Laboratory (Bar Harbor, ME). SV129J-wt and PPAR $\alpha$ null mice ranged from 3 to 4 months of age, with average body weight of $22 \pm 3 \mathrm{~g}$ for wild-type and $21 \pm 2 \mathrm{~g}$ for KO mice. Animals were fed standard laboratory chow diet $(4.5 \%$ fat, $20 \%$ protein and $54.8 \%$ carbohydrate by weight) (PICOLab Rodent Diet 20; 5053) and maintained under 12-h light/ dark conditions (6:00 AM/6:00 PM) for clamp and body analysis studies, (7:00 AM/7:00 PM) for stable isotope labeled glucose test and hepatic glucose production studies.

\subsubsection{Stable isotope labeled glucose tolerance test (SiGTT) and hepatic glucose production (HGP) studies}

Around ten mice each of PPAR $\alpha$ null, SV129J-wt males maintained on chow diet before they were switched to high fat/high carbohydrate diet $35 \%$ fat and $33 \%$ carbohydrate by weight, F3282; Bioserve, Frenchtown, NJ). They were fed high fat diet for 4 weeks, before being studied. Stable isotope labeled glucose tests and hepatic glucose production studies were done as in our previous studies (Xu et al. 2002, 2003, 2004, 2006a, 2006b). Briefly, mice were fasted at $7 \mathrm{PM}$ and an intra peritoneal injection of glucose was done $(1.0 \mathrm{mg} / \mathrm{g}$ body weight, containing $50 \%\left[6,6-{ }^{2} \mathrm{H}_{2}\right]$-glucose) at $10 \mathrm{AM}$ next morning. Each point of the stable isotope glucose tolerance test was the average of 5 mice. Blood samples for insulin and glucose analysis were collected at various time points as indicated in Fig. 3. $\left[6,6{ }^{2} \mathrm{H}_{2}\right]$-glucose was $>98 \%$ enriched and sterility/pyrogenicity tested by the manufacturer (Cambridge Isotope Laboratories, MA). GC/MS analyses of plasma glucose isotopomers during the stable isotope labeled glucose tolerance test can be found in our previous paper (Xu et al. 2002, 2003, 2004). Briefly 50-100 $\mu \mathrm{l}$ of plasma were deproteinized, deionized, and dried. The glucose was treated with hydroxylamine hydrochloride and then acetic anhydride to create aldonitrile pentaacetate derivative, which was dissolved in $150 \mu$ l ethyl acetate for GC/MS analysis.

\subsubsection{Stable isotope assessment of hepatic glucose production and clearance}

Determination of hepatic glucose production was carried out by constant infusion of $\left[\mathrm{U}_{-}{ }^{13} \mathrm{C}_{6}\right]$-glucose $(99 \%$ enriched, Cambridge Isotope Laboratories, MA) through a mini-osmotic pump (Alza model 2001D, duration $24 \mathrm{~h}$ ) (Xu et al. 2002). Four PPAR $\alpha$ null and SV129J-wt males each were examined at 16-18 weeks of age. Briefly, 
fasting of animals was initiated at $4 \mathrm{PM}$, and a mini-osmotic pumps containing $0.25 \mathrm{mg} / \mu \mathrm{l}$ of $\left[\mathrm{U}_{-}{ }^{13} \mathrm{C}_{6}\right]$-glucose was quickly inserted to subcutaneous space of an animal at $7 \mathrm{PM}$ under $\sim 5 \%$ isoflurane. Blood samples were collected by retro-orbital bleeding at $10 \mathrm{AM}$ next morning. Hepatic glucose production (HGP) rate was determined using the following equation: HGP (mg glucose/kg body weight/ $\min )=$ infusion rate $\times\left(1 / \mathrm{E}_{\text {Tracer }}-1\right)$. In the basal state, $\mathrm{HGP}=$ basal glucose disposal, and clearance is defined as (HGP/[Basal glucose]). The infusion rate $(\mathrm{mg} / \mathrm{kg} / \mathrm{min})=$ miniosmotic pump rate $(8 \mu \mathrm{l} / \mathrm{h}$ calibrated by the manufacturer $) \times\left[\mathrm{U}_{-}{ }^{13} \mathrm{C}_{6}\right]$-glucose concentration $(0.25 \mathrm{mg} / \mu \mathrm{l}) /$ mouse body weight $(\mathrm{kg})$. $\mathrm{E}_{\text {Tracer }}$ is the enrichment of plasma $\left[\mathrm{U}^{13} \mathrm{C}_{6}\right]$-glucose determined by gas chromatography/mass spectrometry (GC/MS) analysis. GC/MS conditions, sample preparations for GC/MS analysis, and a detailed description of equations and calculations for HGP can be found in our previous papers (Xu et al. 2002, 2006a).

\subsubsection{Euglycemic hyperinsulinemic and hyperglycemic clamp studies}

Clamp experiments were performed using mice at 12-14 weeks old, in chronically catheterized conscious mice in the Mouse Metabolic Phenotyping Center at Vanderbilt University Medical Center. Animals were fed high-fat diet for 8 weeks euglycemic clamp or 3 weeks hyperglycemic clamp, respectively. The catheters were implanted in the carotid artery and jugular vein for sampling and infusions, respectively. The surgical procedures utilized are similar to those described previously (Ayala et al. 2006). Animals were individually housed after surgery, and body weight was recorded daily. The success rate of the surgery and catheterization procedures was $\sim 70 \%$. Mice were allowed to recover from surgery for at least 3-4 days and were only studied when body weight was restored to within $10 \%$ of pre-surgery body weight. All procedures performed were approved by the Vanderbilt University Animal Care and Use Committee. After 3-4 days of recovery, $4 \mathrm{~h}$ fasted conscious mice underwent one of two protocols ( $n=5-7$ in all groups). After basal sampling at time 0 , insulin was continuously infused at $2.5 \mathrm{mU} \mathrm{kg}^{-1} \mathrm{~min}^{-1}$ for the duration of the 2-h study (euglycemic clamp). Blood glucose levels were monitored using a HemoCue glucose analyzer (HemoCue; Mission Viejo, CA). Glucose was infused at a variable rate to maintain clamped blood glucose levels at $120 \mathrm{mg} /$ dl (EG clamp), and $220 \mathrm{mg} / \mathrm{dl}$ (HG clamp), a primed $(5 \mu \mathrm{Ci})$ continuous $(0.05 \mu \mathrm{Ci} / \mathrm{min})$ infusion $3{ }^{3} \mathrm{H}$ glucose was initiated $120 \mathrm{~min}(t=-120 \mathrm{~min})$ prior to initiating the clamps. Plasma sampled prior just prior to the clamp onset $\left(t-0^{-}\right)$was used to calculate basal glucose disposal and clearance. Then the tracer infusion rate was increased to $0.1 \mu \mathrm{Ci} \min$ at the onset of the clamp $(t=0 \mathrm{~min})$ and infused throughout the study. At $t=120 \mathrm{~min}$ mice received a $13 \mathrm{mCi}$ bolus of 2 -deoxy $\left[{ }^{14} \mathrm{C}\right]$ glucose $(2 \mathrm{DG})$ to provide an index of muscle glucose uptake (MGU) by measuring the accumulation of 2DG-phosphate (2DG-P). During the experimental period, a continuous infusion of donor blood was used to replace blood removed. After taking the last blood sample $(t=145 \mathrm{~min})$, mice were anesthetized with an infusion of sodium pentobarbital. The adipose tissue, brain, liver, gastronemius, soleus and vastus were excised, freezeclamped immediately in liquid nitrogen, and stored at $-70^{\circ} \mathrm{C}$ until future tissue analysis.

\subsubsection{Body composition}

Body composition was determined for each animal by low resolution nuclear magnetic resonance (NMR) Percentage lean mass and fat mass were calculated as a proportion of the total body weight of the animal. $\operatorname{PPAR} \alpha$ null $(n=10)$ and SV129J-wt $(n=9)$ males were examined by NMR prior to placing animals on a high fat diet and at 3 and 8 weeks on the high fat diet.

\subsubsection{Indirect calorimetry}

Metabolic parameters ( $n=7-8$ /group) were measured using an Oxymax (Columbus Instruments, Columbus, $\mathrm{OH}$ ) 8 cage open circuit indirect calorimetry system.

Oxygen consumption $\left(\mathrm{V}_{\mathrm{O}_{2}}\right)$ and the respiratory exchange ratio (RER) were measured by an Oxymax indirect calorimeter (Columbus Instruments, Columbus, $\mathrm{OH}$ ) with an air flow of $0.751 / \mathrm{min}$. $\mathrm{V}_{\mathrm{O}_{2}}$ is expressed as the volume of $\mathrm{O}_{2}$ consumed per kilogram body weight per hour. After $1 \mathrm{~h}$, to allow for adaptation to the metabolic chamber, $\mathrm{V}_{\mathrm{O}_{2}}$ was measured, starting at 10:00 AM, in individual mice for $1 \mathrm{~min}$ at 15 -min intervals for a total of $22 \mathrm{~h}$ under a consistent environmental temperature $\left(22^{\circ} \mathrm{C}\right)$. The respiratory exchange ratio (RER) is the ratio of the volume of $\mathrm{CO}_{2}$ produced to the volume of $\mathrm{O}_{2}$ consumed.

Mice were individually housed in the chamber for $48 \mathrm{~h}$ with lights on from 0600 to 1800 in an ambient temperature of $22-24^{\circ} \mathrm{C}$. Food was available ad libitum during the dark cycle (feeding phase 1800-0600) and the light cycle (fasting phase 0600-1800). Gas exchange measurements were made under Oxymax system settings as follows: air flow, $0.6 \mathrm{l} / \mathrm{min}$; sample flow, $0.5 \mathrm{l} / \mathrm{min}$; settling time, $6 \mathrm{~min}$; and measuring time, $3 \mathrm{~min}$.

All animal studies were performed under approved institutional protocols and according to guidelines established in the Guide for the Care and Use of Laboratory Animals. 


\subsubsection{Biochemical/serum analysis}

The plasma glucose level was determined by COBAS MIRA analyzer (Roche, Montclair, NJ) using Glucose UV Reagent (catalog no. 80017, Raichem, San Diego, CA). Plasma insulin was determined using ultra sensitive rat/ mouse Insulin ELISA Kit (Crystal Chem. Inc., Cat\# 90060).

\subsubsection{Statistical analyses}

All data were expressed as mean \pm SEM, except for data in Table 1 and the inset tables in Figs. 4 and 5, presented as mean \pm standard deviation (SD) Analyses for the significance of differences were performed using Student's $t$-test.

\section{Results}

\subsection{The PPAR $\alpha$ null mouse is metabolically inflexible}

Since the previous metabolic studies utilizing clamps (Haluzik et al. 2004) or unlabeled intra-peritoneal glucose tolerance tests (Guerre-Millo et al. 2001) used the PPAR $\alpha$ null mouse on a SV129J background, this background was used for this study. The influence of PPAR $\alpha$ on metabolic flexibility was first examined by indirect calorimetry. Figure 1 shows that in the chow fed state, glucose utilization substitutes for fatty acid utilization during the light cycle. In the light cycle, fatty acid utilization normally increases with time, as seen here for the SV129J-wt by the respiratory exchange ratio ( $\mathrm{RER}=\mathrm{V}_{\mathrm{CO}_{2}} / \mathrm{V}_{\mathrm{O}_{2}}$ ) progressively decreasing from 0.95 , just when the dark cycle ends, to 0.78 at the end of the light cycle. For the PPAR $\alpha$ null mice, there is an increase in the respiratory exchange ratio (RER) from 0.85 to 0.95 during the light cycle, and remains elevated during most of the light cycle, a state of metabolic inflexibility.

High fat feeding for 8 weeks represents a chronic deleterious stimulus for assessment of PPAR $\alpha$ deficiency on fuel utilization. After 8 weeks on a high fat diet, oxygen consumption $\left(\mathrm{V}_{\mathrm{O}_{2}}\right)$ (Fig. 1), calculated (default by the Oxymax software) per kg of total body weight was lower for the PPAR $\alpha$ null mice, suggesting a lower metabolic rate. The diurnal substrate utilization appears identical for both PPAR $\alpha$ null and the SV129J-wt mice.

However, oxygen consumption $\left(\mathrm{V}_{\mathrm{O}_{2}}\right)$ normalized for lean body mass is virtually identical for the PPAR $\alpha$ null and wild type mice (data not shown). Figure 2 shows the assessment of fat and muscle by low resolution quantitative NMR. Lean muscle mass is not significantly different for the PPAR $\alpha$ null and SV129J-wt mice.

These results suggest that compensations have occurred in response to this high fat diet, a case of extreme substrate excess. These compensations allow for the matching of metabolic rate/substrate utilization, but at the cost of weight gain for the PPAR $\alpha$ null mice. These results are consistent with the mice having a fixed energy need, matched for SV129J-wt and PPAR $\alpha$ null mice, independent of their diet, and dependent on lean muscle mass. The results also indicate that while indirect calorimetry can be useful in the detection of "metabolically silent" phenotypes, measurement of simply the diurnal variation in fuel utilization or oxygen consumption cannot assess the underlying fuel compensations that maintain whole body energy needs.

Table 1 Effect of diet on dynamic glucose disposal, as assessed using stable isotope glucose tolerance test (either a ${ }^{13} \mathrm{C}_{1,2}$ glucose or a $\left[6,6-{ }^{2} \mathrm{H}\right]-$ glucose)

\begin{tabular}{|c|c|c|c|c|}
\hline & \multicolumn{2}{|l|}{ Chow diet } & \multicolumn{2}{|l|}{ High fat diet } \\
\hline & $\mathrm{WT}(n=6)$ & $\mathrm{KO}(n=5)$ & $\mathrm{WT}(n=6)$ & $\mathrm{KO}(n=5)$ \\
\hline Body weight (mg) & $27 \pm 1.9$ & $31 \pm 1.9 * *$ & $32 \pm 3.0$ & $34 \pm 2.9 *$ \\
\hline Fasting plasma glucose (mg/dl) & $150 \pm 25$ & $109 \pm 27 *$ & $169 \pm 22$ & $97 \pm 18^{* * *}$ \\
\hline Fasting plasma insulin (ng/ml) & $0.16 \pm 0.06$ & $0.32 \pm 0.09 * *$ & $0.462 \pm 0.12$ & $0.26 \pm 0.11 *$ \\
\hline AUC plasma glucose $(\mathrm{mg} / \mathrm{dl} \times \mathrm{h})$ & $237.1 \pm 25.44$ & $125.2 \pm 20.92 * *$ & $352.7 \pm 29.01^{\S}$ & $191.5 \pm 16.52 * * * \dagger$ \\
\hline AUC plasma insulin $(\mathrm{ng} / \mathrm{ml} — \mathrm{~h})$ & $0.11 \pm 0.054$ & $0.53 \pm 0.20^{*}$ & $0.30 \pm 0.12$ & $0.13 \pm 0.10$ \\
\hline $2 \times$ AUC plasma $\left[6,6-{ }^{2} \mathrm{H}_{2}\right]$ glucose $(\mathrm{mg} / \mathrm{dl}-2 \mathrm{~h})$ & $128 \pm 12$ & $96 \pm 6^{*}$ & $244 \pm 14$ & $162 \pm 18 * * *$ \\
\hline AUC plasma $\left[1,2-{ }^{13} \mathrm{C}\right]$ glucose $(\mathrm{mg} / \mathrm{dl} \times \mathrm{h})$ & - & - & $289.3 \pm 11.1$ & $171.9 \pm 12.55^{* * *}$ \\
\hline
\end{tabular}

KO represents PPAR $\alpha^{-1-}$ and WT represents SV129J-wt. The areas under the curve (AUC) are compared for plasma glucose, [6,6- $\left.{ }^{2} \mathrm{H}_{2}\right]-$ glucose and $\left[1,2-{ }^{13} \mathrm{C}\right]$ glucose and insulin, between WT and PPAR $\alpha^{-1-}$ mice during the 2-h time course of intraperitoneal SiGTT (1 mg/g body weight). For the $\left[6,6-{ }^{2} \mathrm{H}_{2}\right]$-glucose tolerance test, since the glucose injected was only $50 \%$ enriched in $\left[6,6-{ }^{2} \mathrm{H}_{2}\right]$-glucose, a factor of 2 is necessary for comparison of the $\left[6,6-{ }^{2} \mathrm{H}_{2}\right]$-glucose area under the curve to the total glucose area under the curve. $\left[1,2-{ }^{13} \mathrm{C}\right]$ glucose has already been used by us to evaluate PPAR $\alpha^{-1-}$ mice under chow fed conditions (Xu et al. 2004) and so this was not repeated here. Data are presented as mean \pm SD. *** $P<0.001$, ** $P<0.01$, * $P<0.05$ between the respective WT and PPAR $\alpha^{-l-}$ mice and ${ }^{\S}$ represents $P<0.0001$ for chow versus high fat fed WT and ${ }^{\dagger}$ represents $P<0.01$ for chow versus high fat fed PPAR $\alpha^{-/-}$mice determined by student's $t$-test 


\section{A Chow Diet}

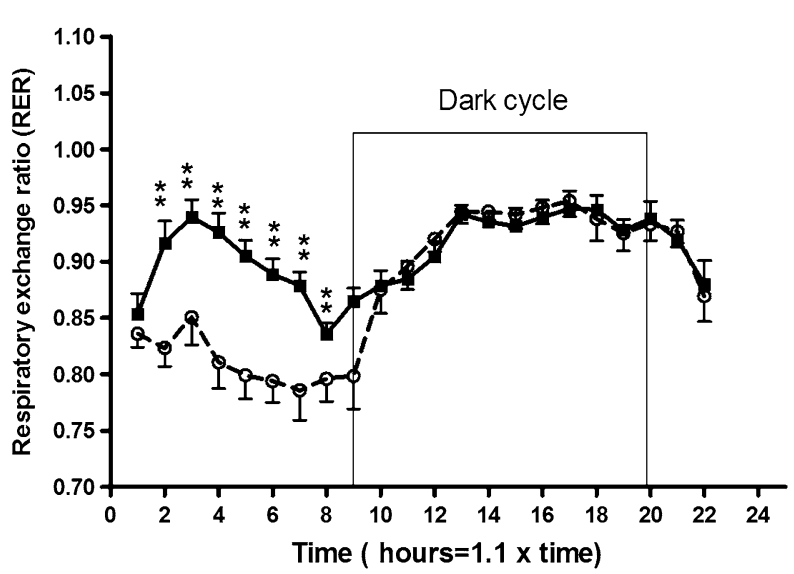

\section{B High fat Diet}

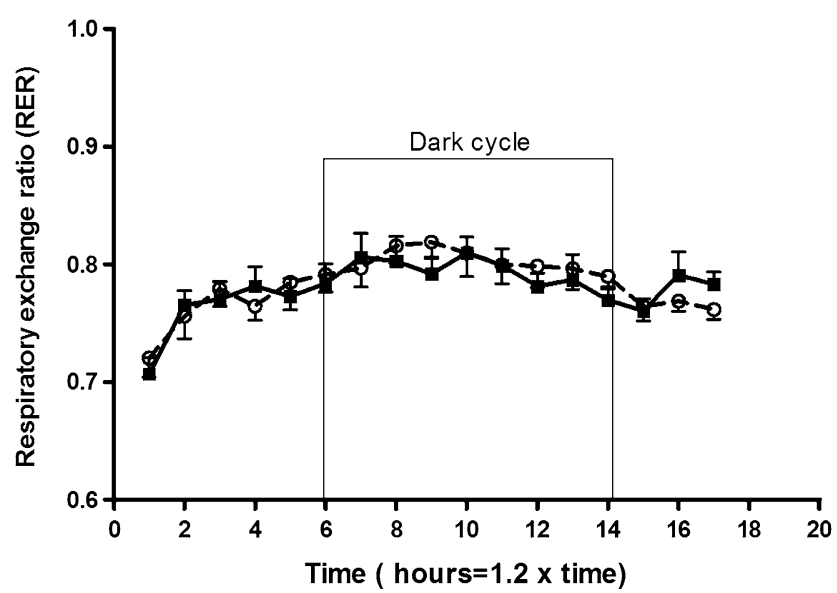

Fig. 1 Indirect calorimetry of PPAR $\alpha$ null and SV129J-wt mice during the fasted to fed transition. The units for the time axis indicate the dark cycle is $12 \mathrm{~h}$ in duration. RER is dimensionless, and oxygen consumption is expressed as $\mathrm{ml}$ of $\mathrm{O}_{2}$ consumed per $\mathrm{kg}$ of whole body mass per min. For chow fed mice, energy expenditure is preserved in the absence of PPAR $\alpha$, but diurnal substrate utilization is affected by

\subsection{Evaluation of the "silent" PPAR $\alpha$ null mice metabolic phenotype-dynamic versus static assessment of glucose disposal}

The increased reliance on carbohydrate as a primary fuel for the $\operatorname{PPAR} \alpha$ null mice shown by indirect calorimetry (Fig. 1), led us to examine glucose disposal in the chow fed versus high fat fed PPAR $\alpha$ null mouse models. Two methods were compared. One, using a stable isotope labeled glucose tolerance test shown to evaluate "dynamic" glucose disposal during the glucose tolerance test. Stable isotope labeled glucose tolerance tests has been effective in evaluating "silent" metabolic phenotypes (Xu et al. 2004, 2006a). The other were traditional, gold standard methods,
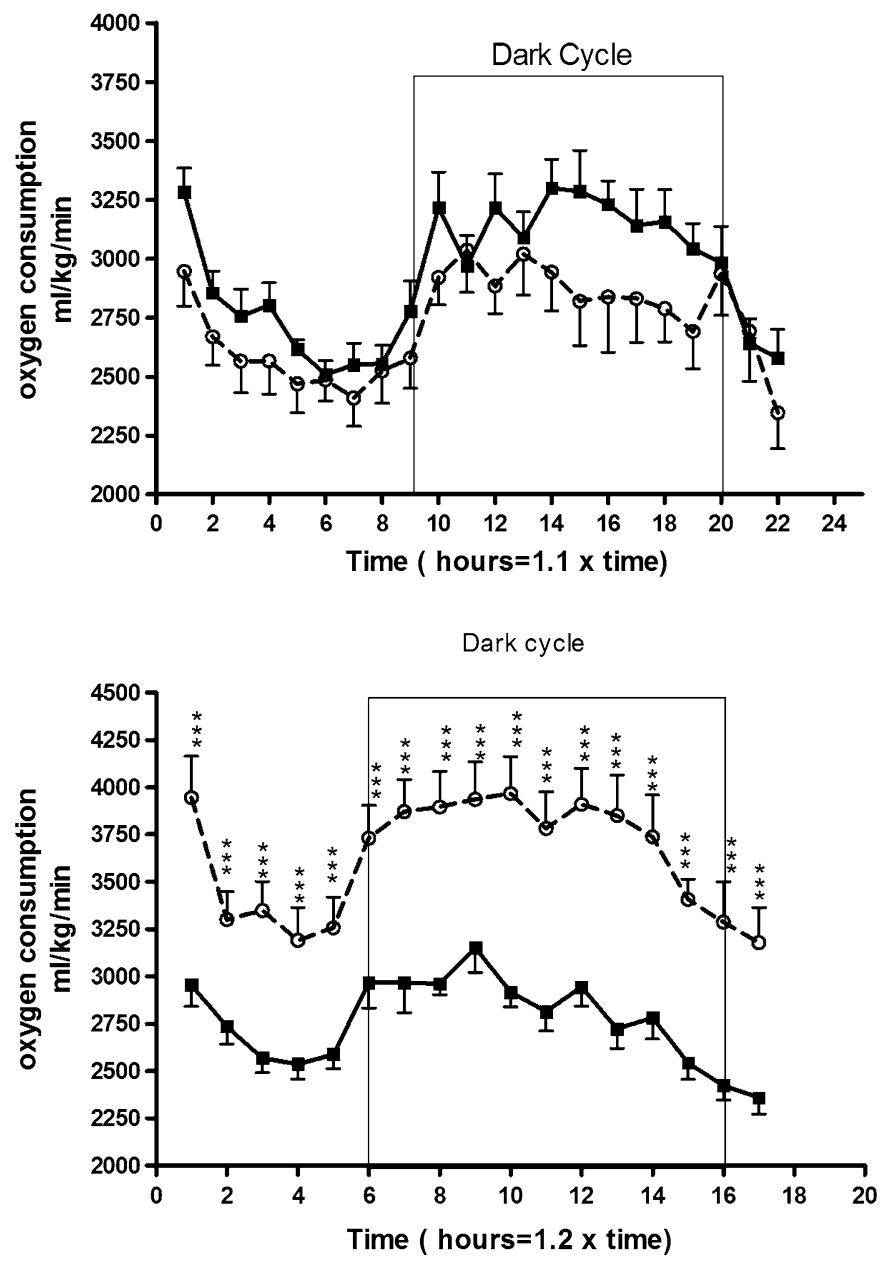

the absence of PPAR $\alpha$. There are no significant differences in $V_{\mathrm{O}_{2}}$ for high fat fed PPAR $\alpha$ null and SV129J-wt mice when normalized by lean muscle mass, as opposed to the differences seen here when normalized by their whole body mass (see text and Fig. 2). Data are mean \pm SEM. $* P<0.05$, ** $P<0.01$, *** $P<0.001$ PPAR $\alpha$ null versus SV129J-wt mice

that give a "static" evaluation of glucose disposal at fixed glucose levels, the euglycemic-hyperinsulinemic (EU) clamp, and the hyperglycemic (HG) clamp. The euglycemic clamp accurately evaluates glucose disposal for basal glucose at a fixed high insulin level. However, the prior use of the euglycemic clamp in the PPAR $\alpha$ null mouse model revealed no difference in glucose disposal under high fat feeding conditions (Haluzik et al. 2004). This is in contrast to an unlabeled glucose tolerance test that showed a smaller glucose excursion with a smaller insulin response during a glucose tolerance test for the high fat fed PPAR $\alpha$ null versus wild type mice (Guerre-Millo et al. 2001).

For this study, we used a stable isotope labeled intra peritoneal glucose tolerance test that employed either 

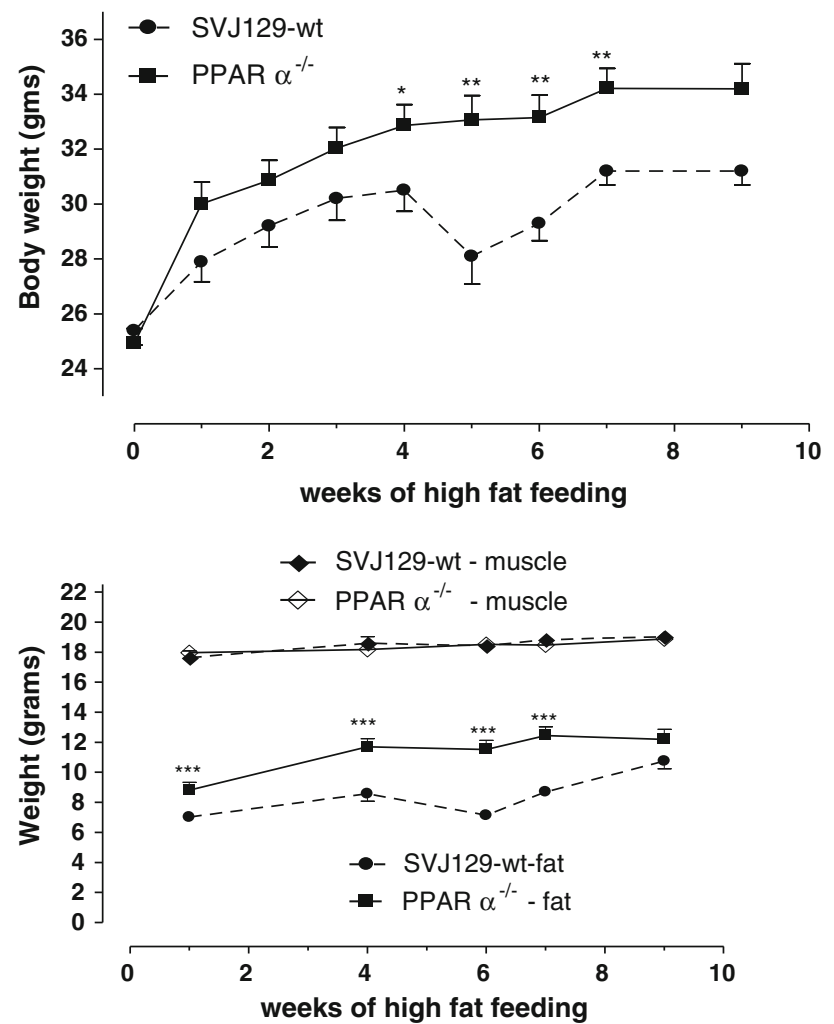

Fig. 2 Body composition studies. PPAR $\alpha$ null mice gain weight more quickly on a high fat, high carbohydrate diet (Bioserve Product\# F3282, see Methods Sect. 2). The fat mass is higher for the PPAR $\alpha$ null in comparison to the SV129J-wt mice. Lean muscle mass is not significantly different for the PPAR $\alpha$ null and wild type mice. Data are mean \pm SEM. $* P<0.05$, ** $P<0.01$, *** $P<0.001$ PPAR $\alpha$ null versus SV129J-wt mice

$\left[1,2-{ }^{13} \mathrm{C}\right]$-glucose or $\left[6,6-{ }^{2} \mathrm{H}\right]$-glucose for glucose disposal at $1 \mathrm{mg}$ glucose/g body weight (see Sect. 2). Figure 3 and Table 1 summarize a comparison of the results shown.

The data demonstrates the utility of using this stable isotope labeled glucose tolerance test over a conventional glucose tolerance test. For the chow fed studies, the area under the curve for plasma glucose (labeled and unlabeled) for the SV129J-wt during the glucose tolerance test is significantly higher than the area under the curve for $\left[6,6-{ }^{2} \mathrm{H}\right]$-glucose for the PPAR $\alpha$ null mice. This suggests that either the PPAR $\alpha$ null mice have increased glucose disposal, or hepatic glucose production may be less suppressed for the SV129J-wt than the PPAR $\alpha$ null mice during the test. The data implies some component of both may be evident. The area under the curve for plasma insulin was 5-fold less for the SV129J-wt in comparison to the PPAR $\alpha$ null mice. This suggests the possibility of less inhibition of hepatic glucose production during the $\left[6,6-{ }^{2} \mathrm{H}\right]$-labeled glucose tolerance test for the wild type. The PPAR $\alpha$ null mice had a similar area under the curve for total and $\left[6,6-{ }^{2} \mathrm{H}\right]$ plasma glucose. However, the $\operatorname{PPAR} \alpha$ null mice also had a lower area under the curve for $\left[6,6{ }^{2} \mathrm{H}\right]$ glucose than the SV129J-wt mice. This suggests a greater rate of glucose disposal for the chow fed PPAR $\alpha$ null mouse. In contrast, for the SV129-wt mice the area under the curve for plasma $\left[6,6-{ }^{2} \mathrm{H}\right]$-glucose during the glucose tolerance test is nearly 2 -fold less than the area under the curve for total plasma glucose (labeled and unlabeled). This is also consistent with less inhibition of hepatic glucose production during the $\left[6,6-{ }^{2} \mathrm{H}\right]$-labeled glucose tolerance test for the SV129J wt mice.

Figure 3 and Table 1 indicates that after 4 weeks of high fat feeding, the PPAR $\alpha$ null mice showed increased glucose disposal versus the SV129J-wt. Suppression of hepatic glucose production during the stable isotope labeled glucose tolerance test was evident for the high fat fed PPAR $\alpha$ null mice, which had similar area under the curves for the total (labeled and unlabeled) and $\left[6,6-{ }^{2} \mathrm{H}\right]$ plasma glucose. However, during the glucose tolerance test, the SV129J-wt had a 40\% increase in the area under the curve for total glucose versus the $\left[6,6-{ }^{2} \mathrm{H}\right]$ glucose, as opposed to a $18 \%$ increase for the same measurements for the PPAR $\alpha$ null mice (Table 1). This is consistent with the finding that the high fat fed SV129J-wt had a decreased suppression of hepatic glucose production during the $\left[6,6^{2} \mathrm{H}\right]$-glucose tolerance test. Increased peripheral insulin sensitivity for the high fat fed PPAR $\alpha$ null mouse model is supported by stable isotope labeled glucose tolerance test glucose disposal measurements. The areas under the curves for both $\left[6,6-{ }^{2} \mathrm{H}\right]$ glucose or the $\left[1,2-{ }^{13} \mathrm{C}\right]$ glucose was decreased by $\sim 30 \%$ for high fat fed PPAR $\alpha$ null mice compared to the high fat fed SV129J-wt mice, for an identical area under the curve for plasma insulin.

As reviewed by Wolfe and Chinkes (Wolfe 2005) hepatic glucose uptake of $\left[6,6-{ }^{2} \mathrm{H}_{2}\right]$-glucose generally leads to loss of the deuterium label, when 3-carbon pyruvate produced is converted to oxaloacetate and when malate is converted to fumarate in the TCA cycle. Therefore, the $\left[6,6-{ }^{2} \mathrm{H}_{2}\right]$-glucose time course during the $\left[6,6-{ }^{2} \mathrm{H}\right]$-glucose tolerance test represents glucose disposal with minimal, if any, re-circulation through the TCA cycle. However, while theoretically $\left[1,2-{ }^{13} \mathrm{C}\right]$ glucose in the $\left({ }^{13} \mathrm{C}_{1,2}\right.$-glucose tolerance test) can re-circulate through the TCA cycle, Cori cycle, or the hepatic pentose cycle, the area under the curve for $\left[1,2-{ }^{13} \mathrm{C}\right]$ glucose during the ${ }^{13} \mathrm{C}_{1,2}$ glucose tolerance test was similar for both the SV129J-wt and PPAR $\alpha$ null for these high fat fed mice. This indicates that there was minimal re-cycling of the $\left[1,2-{ }^{13} \mathrm{C}\right]$-glucose tracer, and that the use of the ${ }^{13} \mathrm{C}_{1,2}$-labeled glucose tolerance test was equivalent to the $\left[6,6-{ }^{2} \mathrm{H}\right]$-labeled glucose tolerance test, at least for the conditions examined here.

The differences seen in the muscle glucose disposal response during the stable isotope labeled glucose tolerance test were further clarified using the euglycemichyperinsulinemic (EU) clamp, and the hyperglycemic 

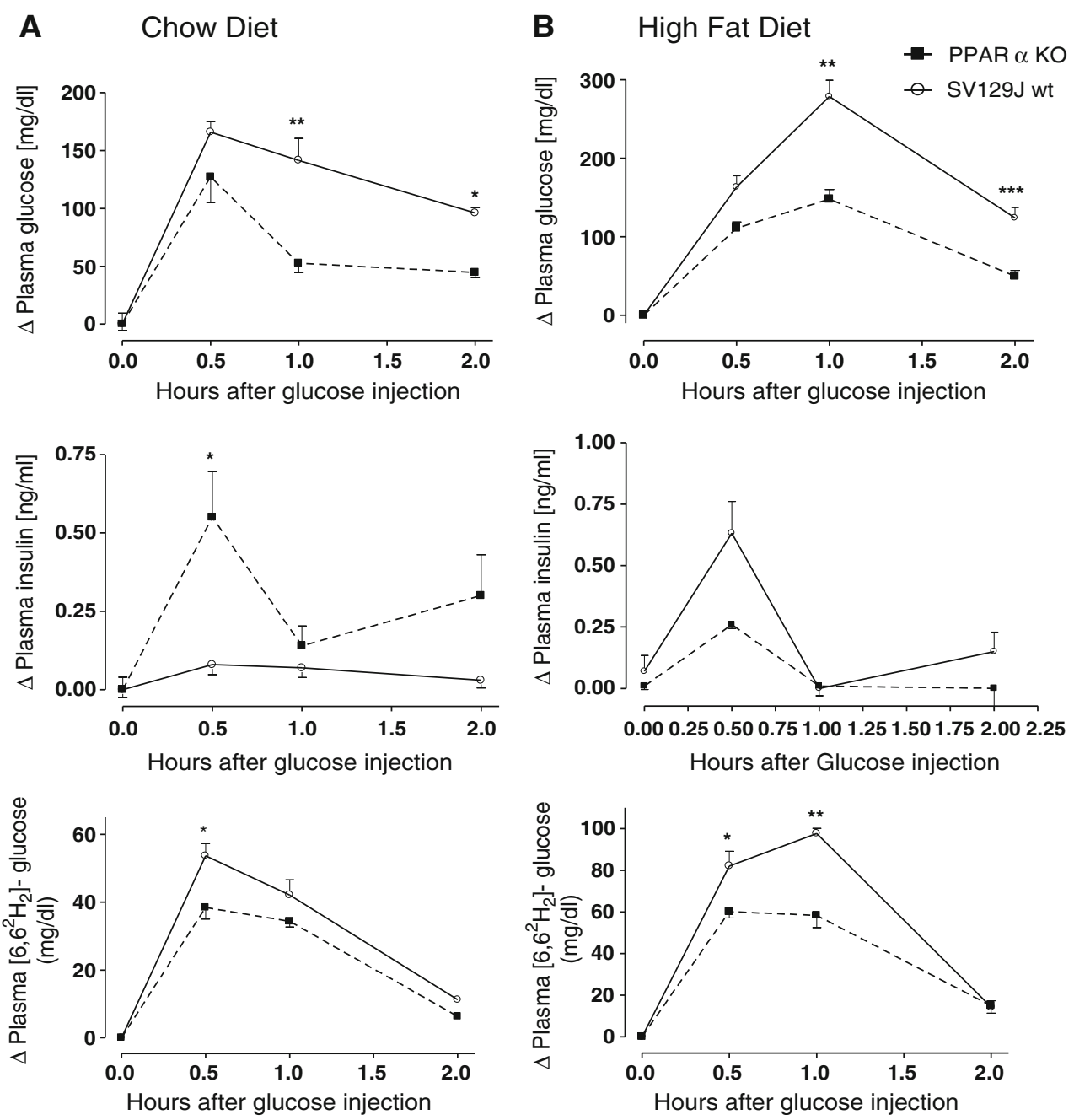

Fig. 3 The effect of the presence or absence of PPAR $\alpha$ on glucose disposal during a stable isotope labeled glucose tolerance test in response to chow diet versus 4 weeks of high fat feeding. Time course of plasma glucose, insulin and $\left(\left[6,6-{ }^{2} \mathrm{H}\right]\right.$ glucose isotopomers from their basal levels is shown. The broken lines represent PPAR $\alpha$ null

mice and the solid lines represent the SV129J-wt. Each point shown represents the mean \pm SEM with five animals in each group. The two tailed $\mathrm{t}$ test was used for all statistical analyses. * $P<0.05$, ** $P<0.01$, *** $P<0.001 \mathrm{PPAR} \alpha$ null versus SV129J-wt mice

clamp (HG). The euglycemic clamp gives an "open loop" measurement of insulin sensitivity, as glucose disposal is measured at basal insulin in response to a given insulin step infusion. The hyperglycemic clamp can be considered to be a "controlled" version of a glucose tolerance test, as hyperglycemic levels are reached for the entire clamp study that are similar to peak levels of glucose during a glucose tolerance test, and the insulin levels seen during the hyperglycemic clamp are responsive to the level of glycemia.

Euglycemic clamps were done in chow fed SV129J-wt and PPAR $\alpha$ null mice, and after 8 weeks of high fat fed feeding. Hyperglycemic clamps were done after 3 weeks of high fat feeding (Table 2). The effect on glucose disposal and rate of appearance (Ra) in the absence of PPAR $\alpha$ for these conditions is summarized in Table 2.

The greatest difference seen in the euglycemic and hyperglycemic clamp studies reflect the basal values, rather than the euglycemic or hyperglycemic clamped states themselves. While the basal glucose values ( $6.5 \mathrm{~h}$ fasted) were similar in the chow fed state, the basal glucose values trended lower for the PPAR $\alpha$ null mice versus SV129J-wt whether for 3 weeks or 8 weeks of high fat fed feeding. For all the animals placed on a high fat diet, total glucose flux decreases in wild type and PPAR $\alpha$ null mice with time, reflected in the glucose clearance (Fig. 4). Glucose clearance is higher for PPAR $\alpha$ null mice in the basal chow fed state, and with high fat fed feeding glucose clearance decreases for both. Statistically there is no difference in glucose clearance for KO versus SV129J-wt at 3 or 8 weeks.

Basal glucose clearance in response to an $18 \mathrm{~h}$ fast, calculated from Alzet mini-pump hepatic glucose 
Table 2 Plasma glucose, insulin and clamp results on different weeks of high fat diet

\begin{tabular}{|c|c|c|c|c|c|c|}
\hline \multirow[t]{2}{*}{ Clamped ( 80-120 min) } & \multicolumn{2}{|c|}{0 weeks (euglycemic clamp) } & \multicolumn{2}{|c|}{3 weeks (hyperglycemic clamp) } & \multicolumn{2}{|c|}{8 weeks (euglycemic clamp) } \\
\hline & $\mathrm{WT}(n=6)$ & $\mathrm{KO}(n=5)$ & WT $(n=6)$ & $\mathrm{KO}(n=5)$ & WT $(n=7)$ & $\mathrm{KO}(n=6)$ \\
\hline Plasma glucose $(\mathrm{mg} / \mathrm{dl})$ & $117 \pm 5$ & $123 \pm 5$ & $217 \pm 3$ & $228 \pm 2$ & $126 \pm 6$ & $130 \pm 7$ \\
\hline Plasma insulin (ng/ml) & $3.3 \pm 0.6$ & $5 \pm 0.7$ & $32 \pm 6.0$ & $27.4 \pm 8.1$ & $3.7 \pm 0.4$ & $4.4 \pm 1.4$ \\
\hline GIR (mg/kg/min) & $52 \pm 4$ & $69 \pm 3$ & $59 \pm 1$ & $44 \pm 0$ & $34 \pm 5.4$ & $34.2 \pm 6.9$ \\
\hline $\mathrm{Ra}(\mathrm{mg} / \mathrm{kg} / \mathrm{min})$ & $80.5 \pm 13$ & $93 \pm 11$ & $49.1 \pm 1$ & $43.2 \pm 1.1$ & $32.4 \pm 5.3$ & $27.7 \pm 2.2$ \\
\hline Endo $\mathrm{Ra}(\mathrm{mg} / \mathrm{kg} / \mathrm{min})$ & $27 \pm 12$ & $25 \pm 8$ & $-10.2 \pm 1.0$ & $-0.5 \pm 1.0$ & $-3.1 \pm 4.9$ & $-6.5 \pm 6.6$ \\
\hline
\end{tabular}

KO represents PPAR $\alpha^{-1-}$ and WT represents SV129J-wt. The table shows clamp results during a euglycemic $(120 \mathrm{mg} / \mathrm{dl}) \mathrm{and} 2.5 \mathrm{mU} / \mathrm{kg} / \mathrm{min}$ insulin and hyperglycemic $(220 \mathrm{mg} / \mathrm{dl})$ clamps. GIR represents glucose infusion rate, Ra represents rate of appearance of glucose. Data represented are values + SEM. A negative value for Endo Ra represents suppression of Endo Ra

Fig. 4 Glucose clearance on chow diet (0 weeks) and 3 and 8 weeks of a high fat diet. Graph data are presented as mean + SEM, table as mean \pm $\mathrm{SD}$, and $*$ indicates statistical significance $(P<0.05)$ between the values of clearance for SV129J-wild type and PPAR $\alpha$ null mice, determined by student's $t$-test. Basal glucose (table and graph) and insulin (table only) are shown for chow diet ( 0 week) and for 3 weeks and 8 weeks of high fat feeding. Data are not statistically different between the SV129Jwt and PPAR $\alpha$ null mice
PPAR $^{-/-}$- Basal Glucose

SV129J-wt-Basal Glucose

-马. PPAR $\alpha^{-/-}$- clearance

๑- SV129J-wt - clearance

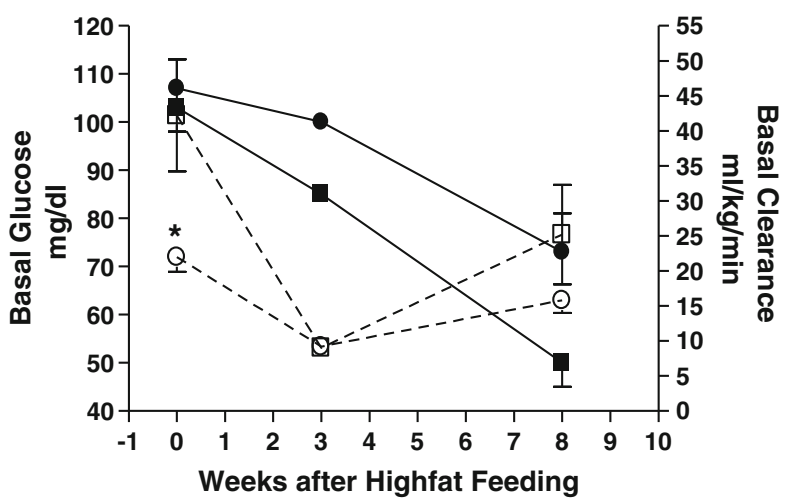

\begin{tabular}{|c|c|c|c|c|cr|}
\hline $\begin{array}{c}\text { Weeks after } \\
\text { High fat }\end{array}$ & \multicolumn{2}{|c|}{0 Week } & \multicolumn{2}{c|}{3 Weeks } & \multicolumn{2}{c|}{8 Weeks } \\
\cline { 2 - 7 } & $\begin{array}{c}\text { SVJ129-wt } \\
(\mathrm{n}=6)\end{array}$ & $\begin{array}{c}\text { PPARa } \\
(\mathrm{n}=5)\end{array}$ & $\begin{array}{c}\text { SVJ129-wt } \\
(\mathrm{n}=7)\end{array}$ & $\begin{array}{c}\text { PPARa } \\
(\mathrm{n}=6)\end{array}$ & $\begin{array}{r}\text { SVJ129-wt PPARa } \\
(\mathrm{n}=6)\end{array}$ & $(\mathrm{n}=5)$ \\
\hline $\begin{array}{c}\text { Basal glucose } \\
(\mathrm{mg} / \mathrm{dl})\end{array}$ & $107 \pm 6$ & $103 \pm 6$ & $100 \pm 1$ & $85 \pm 0$ & $73 \pm 8$ & $50 \pm 5$ \\
\hline $\begin{array}{c}\text { Basal Insulin } \\
(\mathrm{ng} / \mathrm{ml})\end{array}$ & $0.9 \pm 0.1$ & $0.9 \pm 0.1$ & $1.2 \pm 0.2$ & $1.8 \pm 0.9$ & $1.8 \pm 0.4$ & $1.0 \pm 0.1$ \\
\hline
\end{tabular}

production experiments $\left(\mathrm{U}^{13} \mathrm{C}\right.$ glucose), presents a different picture (Fig. 5). The basal glucose clearance and hepatic glucose production, between SV129J-wt and $\operatorname{PPAR} \alpha$ null mice as assessed using the Alzet $\mathrm{U}^{13} \mathrm{C}$ glucose mini-pump, do not differ for the chow fed state. However, hepatic glucose production is decreased, and glucose clearance is increased, for the $\operatorname{PPAR} \alpha$ null mice versus SV129J-wt in the high fat fed state (Fig. 5).

Hyperglycemic clamps were done to assess whether the pancreatic $\beta$-cell had a primary defect in the high fat fed state. A shorter high fat feeding period was used than the euglycemic clamp ( 3 weeks), to examine an effect of high fat feeding on the pancreatic $\beta$-cell in approximately the same time frame as that used for the stable isotope labeled glucose tolerance test. Again, the PPAR $\alpha$ null mice were hypoglycemic in the basal state with respect to the SV129Jwt $(85 \mathrm{mg} / \mathrm{dl}$ vs. $100 \mathrm{mg} / \mathrm{dl}$, respectively, see Fig. 4) for similar basal insulin $(1.8 \pm 0.9 \mathrm{ng} / \mathrm{ml}$ for the PPAR $\alpha$ null, $1.2 \pm 0.2 \mathrm{ng} / \mathrm{ml}$ for the SV129J-wt). However, in response to a glucose infusion that raised the plasma glucose of both groups of mice to approximately $225 \mathrm{mg} / \mathrm{dl}$, the PPAR $\alpha$ null plasma insulin was $27.4 \pm 8.1 \mathrm{ng} / \mathrm{ml}$, and the SV129Jwt plasma insulin was $32 \pm 6.0 \mathrm{ng} / \mathrm{ml}$ (Table 2). This indicates that there is an enormous insulin reserve in high fat fed $\beta$-cells, regardless of the level of $\operatorname{PPAR} \alpha$, when a high constant glucose stimulus is used. This suggests a high 
Fig. 5 HGP and glucose clearance for chow diet and after 4 weeks of high fat fed feeding, for PPAR $\alpha$ null versus SV129J-wt mice, as assessed using Alzet osmotic mini-pump with [U- ${ }^{13} \mathrm{C}_{6}$ ] glucose. Values for the bar graphs are mean \pm SEM with five animals in each group. The two tailed $t$ test was used for all statistical analyses. ${ }^{*} P<0.05$,

** $P<0.01$, *** $P<0.001$ PPAR $\alpha$ null versus SV129J-wt mice on respective diets. Plasma glucose and Insulin (mean \pm SD) are represented in the table shown below the bar graphs

\section{Fasting Hepatic Glucose Production and Clearance during ${ }^{13} \mathrm{UC}_{6}$ Glucose pump}

A Chow Diet

PPAR $\alpha^{-/-}$

SV129J-wt
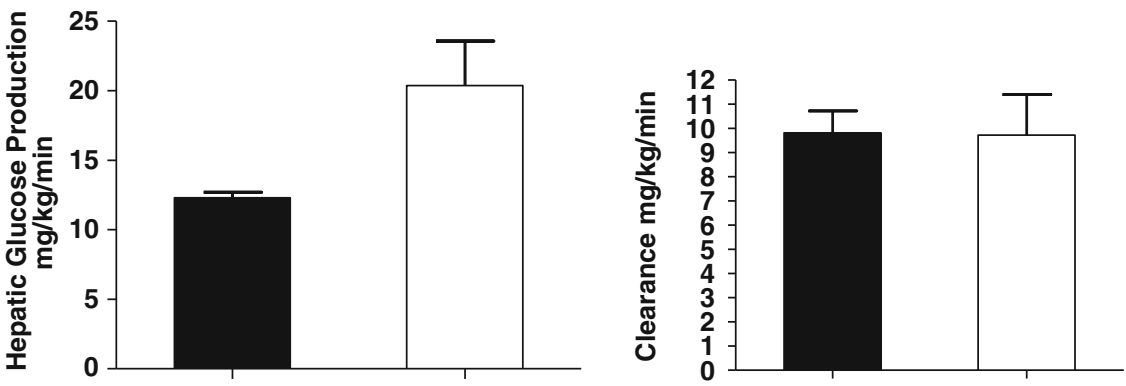

B High fat Diet
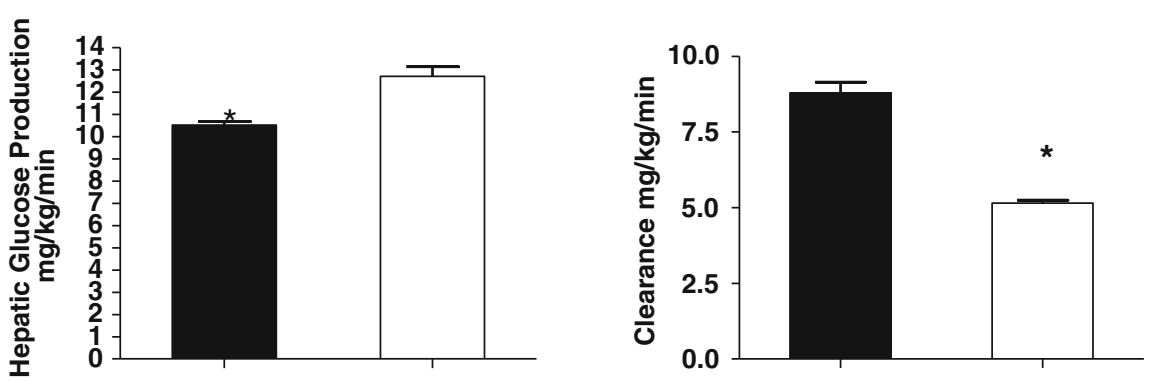

fat induced defect in detecting transient insulin elevations by the pancreatic $\beta$-cell during the stable isotope labeled glucose tolerance tests, as the area under the curve for plasma insulin does not reflect this. As seen in Table 1, we find that there are no differences in the area under the curve for plasma insulin for both the PPAR $\alpha$ null and SV129J-wt mice on a high fat diet, even given the substantial differences in glucose area under the curve for SV129J-wt versus the PPAR $\alpha$ null mice on a high fat diet.

\section{Discussion}

4.1 Advantages of combining static and dynamic approaches for the assessment of in vivo insulin sensitivity and metabolic flexibility

This works suggests ways of combining static and dynamic approaches for optimal assessment of compensatory interactions that maintain fuel homeostasis. It also helps us to determine how these compensatory interactions dictate the development of metabolic flexibility, and/or insulin resistance. The PPAR $\alpha$ null mouse model, due to an inability to oxidize fatty acids, proved ideal for the testing of these complementary approaches. As we have shown here, the PPAR $\alpha$ null mouse model is metabolically inflexible. The present study characterizes the PPAR $\alpha$ null mouse on a SV129J background, as opposed to previous studies on a C57BL/6 background (Xu et al. 2002, 2004). It details the metabolic compensations that have evolved to maintain fuel homeostasis secondary to an inability to oxidize fatty acids, using both static (euglycemic and hyperglycemic clamp clearance measurements (Fig. 4), or Alzet osmotic mini pump measurements of glucose clearance (Fig. 5)), and dynamic (stable isotope labeled intra peritoneal glucose tolerance test) methodologies.

Both dynamic assessment of glucose disposal, and static assessment of basal glucose clearance after an overnight 
fast, reveal the high fat fed PPAR $\alpha$ null mice have increased glucose flux. Using dynamic flux methods, we see that, on a SV129J background, the chow fed PPAR $\alpha$ null mice has a 5-fold greater insulin response during the stable isotope labeled glucose tolerance test than the wild type, supporting the observation of a primary defect in over-secretion of insulin in the PPAR $\alpha$ null mice, on this background (Gremlich et al. 2005). The increased dynamic glucose disposal for the PPAR $\alpha$ nulls on a C57BL/6 mouse background occurs with identical insulin secretion during a stable isotope labeled glucose tolerance test for the C57BL/ 6 background (Xu et al. 2004), indicating increased "peripheral insulin sensitivity" (considering only the glucose and insulin values). This differs for the SV129J background in the chow fed state, as in the chow fed state, there is a 2-fold decrease in the area under the curve for glucose for the PPAR $\alpha$ null mice with a 5-fold increase in the area under the curve for insulin and a $60 \%$ increase in basal insulin versus the respective SV129J-wt (Table 1). The absence of PPAR $\alpha$, whether on a C57BL/6 or SV129J background, results in increased dynamic glucose disposal. For the PPAR $\alpha$ null mouse, on a SV129J background, the increased dynamic glucose disposal may be dependent on the increased insulin secretion seen during the stable isotope labeled glucose tolerance test. This suggests that rather than considering the compensatory mechanisms that preserve fuel homeostasis in terms of changes of insulin sensitivity, one should consider compensatory flux mechanisms that determine dynamic glucose disposal and metabolic flexibility. Further, genetic background has great relevance in determining the ability of organs, such as the pancreas, to adaptively contribute to compensatory flux mechanisms. The smaller insulin response by the PPAR $\alpha$ null mice on the C57BL/6 background genetically may be due to the decrease in $\beta$-cell nicotinamide nucleotide transhydrogenase (Nnt) seen for the C57BL/6 background (Freeman et al. 2006). PPAR $\alpha$ null mouse on both SV129J and C57BL/6 backgrounds has increased peripheral glucose disposal which compensates for the impaired fatty acid oxidation in the chow and high fat fed states, but insulin responses are seen to be different between the two backgrounds only in the chow fed state. Moreover, there is increased peripheral insulin sensitivity seen for the PPAR $\alpha$ null mice in the high fat fed state, but only when assessed dynamically by the stable isotope labeled glucose tolerance test, not with the euglycemic clamp (Table 1, Fig. 3).

The stable isotope labeled glucose tolerance test, by virtue of closed loop and stable isotope assessment of the dynamic response, has advantages in the assessment of glucose disposal over static clamp studies. Euglycemic clamp assessment is an open loop method that requires normalization of the basal glucose values used during the comparative assessments. For the PPAR $\alpha$ null mouse, if the 'euglycemic' clamp assessment were to be done at the SV129J wt value, this value would be hyperglycemic, as the basal glucose value for the PPAR $\alpha$ null mouse is lower than the SV129J wt. Also, the euglycemic clamp neutralizes the adaptive increase in insulin secretion that occurs for the PPAR $\alpha$ null mouse, relative to wt (Table 1), and its effect on glucose disposal. Genetic background, for the PPAR $\alpha$ null mouse, determines the means by which enhanced glucose disposal occurs in the face of a deficiency in fatty acid oxidation.

The implications of the differences implicit in static and dynamic assessments may be profound when designing a phenotyping study. Looking at glucose disposal as a function of the insulin response during a stable isotope labeled glucose tolerance test, or the insulin level during an euglycemic clamp, apparently yields different estimates of whole body insulin sensitivity. Both clamp and stable isotope glucose tolerance test methods have utility. Examining "closed loop" glucose tolerance tests cannot answer how glucose disposal may change for a given increment in plasma insulin, as can be done with the euglycemic clamp. The dynamic "closed loop" stable isotope labeled glucose tolerance test, however, may be ideal for initial assessment of hepatic and/or peripheral insulin resistance, and may yield information concerning adaptive, responses that maintain overall fuel homeostasis that even indirect calorimetry cannot detect. The results of this study may also provide investigators a rationale for use of dynamic methods for screening for initial assessments of insulin resistance before clamp studies are done, as a "triage" to help with decisions in phenotyping assessments.

Acknowledgements This work was supported by grants from National Institutes of Health Grant (R01 DK58132-07) (to I.J.K.), UCLA Center of Excellence in Pancreatic disease (P01 AT003960, W.N.P.L.), Harbor-UCLA GCRC Mass Spectrometry Core (M01 RR00425, W.N.P.L.), the Vanderbilt Mouse Metabolic Phenotyping Center (DK 59637) and (R21 DK 064877, O.P.M.).

Open Access This article is distributed under the terms of the Creative Commons Attribution Noncommercial License which permits any noncommercial use, distribution, and reproduction in any medium, provided the original author(s) and source are credited.

\section{References}

Ayala, J. E., Bracy, D. P., McGuinness, O. P., \& Wasserman, D. H. (2006). Considerations in the design of hyperinsulinemic-euglycemic clamps in the conscious mouse. Diabetes, 55, 390-397.

Desvergne, B., Michalik, L., \& Wahli, W. (2006). Transcriptional regulation of metabolism. Physiological Reviews, 86, 465-514.

Freeman, H., Shimomura, K., Horner, E., et al. (2006). Nicotinamide nucleotide transhydrogenase: A key role in insulin secretion. Cell Metabolism, 3(1), 35-45.

Galgani, J., \& Ravussin, E. (2008). Energy metabolism, fuel selection and body weight regulation. International Journal of Obesity (2005), 32(Suppl 7), S109-S119. 
Gremlich, S., Nolan, C., Roduit, R., Burcelin, R., Peyot, M. L., Delghingaro-Augusto, V., et al. (2005). Pancreatic islet adaptation to fasting is dependent on peroxisome proliferator-activated receptor alpha transcriptional up-regulation of fatty acid oxidation. Endocrinology, 146, 375-382.

Guerre-Millo, M., Rouault, C., Poulain, P., Andre, J., Poitout, V., Peters, J. M., et al. (2001). PPAR-alpha-null mice are protected from high-fat diet-induced insulin resistance. Diabetes, 50, 2809-2814.

Haluzik, M., Gavrilova, O., \& LeRoith, D. (2004). Peroxisome proliferator-activated receptor-alpha deficiency does not alter insulin sensitivity in mice maintained on regular or high-fat diet: Hyperinsulinemic-euglycemic clamp studies. Endocrinology, 145, 1662-1667.

Kelley, D. E. (2005). Skeletal muscle fat oxidation: Timing and flexibility are everything. The Journal of Clinical Investigation, $115,1699-1702$.

Kelley, D. E., \& Mandarino, L. J. (2000). Fuel selection in human skeletal muscle in insulin resistance: A reexamination. Diabetes, 49, 677-683.

Kiens, B. (2006). Skeletal muscle lipid metabolism in exercise and insulin resistance. Physiological Reviews, 86, 205-243.

Petersen, K. F., \& Shulman, G. I. (2006). Etiology of insulin resistance. American Journal of Medicine, 119, S10-S16.

Randle, P. J. (1986). Fuel selection in animals. Biochemical Society Transactions, 14, 799-806.

Randle, P. J. (1995). Metabolic fuel selection: General integration at the whole-body level. The Proceedings of the Nutrition Society, $54,317-327$.
Shulman, G. I. (2000). Cellular mechanisms of insulin resistance. The Journal of Clinical Investigation, 106, 171-176.

Wolfe, R. R. C. D. (2005). Isotope tracers in metabolic research (2nd ed.). New York: Wiley.

Xu, J., Chang, V., Joseph, S. B., Trujillo, C., Bassilian, S., Saad, M. F., et al. (2004). Peroxisomal proliferator-activated receptor alpha deficiency diminishes insulin-responsiveness of gluconeogenic/glycolytic/pentose gene expression and substrate cycle flux. Endocrinology, 145, 1087-1095.

Xu, J., Gowen, L., Raphalides, C., Hoyer, K. K., Weinger, J. G., Renard, M., et al. (2006a). Decreased hepatic futile cycling compensates for increased glucose disposal in the Pten heterodeficient mouse. Diabetes, 55, 3372-3380.

Xu, J., Lee, W. N., Phan, J., Saad, M. F., Reue, K., \& Kurland, I. J. (2006b). Lipin deficiency impairs diurnal metabolic fuel switching. Diabetes, 55, 3429-3438.

Xu, J., Lee, W. N., Xiao, G., Trujillo, C., Chang, V., Blanco, L., et al. (2003). Determination of a glucose-dependent futile recycling rate constant from an intraperitoneal glucose tolerance test. Analytical Biochemistry, 315, 238-246.

Xu, J., Xiao, G., Trujillo, C., Chang, V., Blanco, L., Joseph, S. B., et al. (2002). Peroxisome proliferator-activated receptor alpha (PPAR alpha) influences substrate utilization for hepatic glucose production. The Journal of Biological Chemistry, 277, 50237-50244. 